\title{
Short communication: The effect of increasing concentrations of different methionine forms and 2-hydroxy-4-(methylthio)butanoic acid on genes controlling methionine metabolism in primary bovine neonatal hepatocytes
}

Qian Zhang* and Heather M. White†

Department of Dairy Science, University of Wisconsin, Madison 53706

\section{ABSTRACT}

The D-isomer of Met cannot be used directly by the mammary gland in dairy cows; instead, it is transformed into L-Met, the proteogenic isomer, in the liver and other extramammary tissues. It remains unclear whether different Met forms and a Met hydroxy analog, 2-hydroxy-4-(methylthio)butanoic acid (HMB), are metabolized and function similarly in the liver. The objective of the present study was to examine the regulation of key genes in Met regeneration, transulfuration, and transmethylation pathways in response to increasing doses of different Met forms. Hepatocytes isolated from 4 calves between 4 and $7 \mathrm{~d}$ old were maintained as monolayer cultures for $24 \mathrm{~h}$ before addition of treatments. Treatments of $(0,10,20,40 \mu M)$ D-Met, L-Met, DL-Met, DL-HMB, or a 1:1 mixture of DL-Met and DL-HMB were added to Met-free medium in triplicate. After $24 \mathrm{~h}$, cell lysates were collected for quantification of gene expression by quantitative PCR, and mRNA abundance was normalized to the mean of 3 reference genes. Data were analyzed with PROC MIXED of SAS 9.3 (SAS Institute Inc., Cary, NC). Analyses of covariance confirmed equivalent slopes of Met form, and the final model included form, dose, and random effect of calf within form. Data are reported as least squares means \pm standard error. No main effect of Met form was observed for any genes examined. The enzymes encoded by betaine-homocysteine methyltransferase $(B H M T)$ and 5-methyltetrahydrofolate-homocysteine methyltransferase use betaine and 5-methyltetrahydrofolate, respectively, to regenerate Met from homocysteine. Increasing concentration of Met did not alter 5-methyltetrahydrofolate expression, but decreased BHMT expression. Expression of glycine N-methyltransferase, the enzyme that controls transmethylation flux from S-adenosyl-methionine, was not affected by Met con-

Received May 22, 2018.

Accepted September 19, 2018.

*Current address: Adisseo Life Science Co., Ltd., Shanghai 201204, P.R. China.

$\dagger$ Corresponding author: heather.white@wisc.edu centration. Methionine concentration had no effect on expression of cystathionine $\beta$-synthase, a key enzyme for the transulfuration pathway. The decrease in BHMT expression indicates a decreased need for cellular Met regeneration with increasing Met concentration, independent of Met form. The lack of differences among Met forms on regulating genes examined indicates that all Met forms similarly reduced genes controlling Met regeneration and metabolism in primary bovine hepatocytes.

Key words: methionine isomer, methionine regeneration, 2-hydroxy-4-(methylthio)butanoic acid, transmethylation

\section{Short Communication}

Methionine is a limiting AA for protein synthesis in growing (Donahue et al., 1985) and lactating dairy cattle (Schwab et al., 1976, 1992; NRC, 2001). In addition to protein synthesis, Met serves multiple important biological roles (Figure 1). Utilization of D- and L-isomers of AA are AA- and species-dependent. In dairy cows, the D-Met isomer cannot be directly used by the mammary gland; instead, it is converted into L-Met, the proteogenic isomer, in liver and other extramammary tissues (Lapierre et al., 2012). Despite this need for conversion of D-Met to L-Met, supplementation of rumen-protected DL-Met or the isopropyl ester of 2-hydroxy-4-(methylthio)butanoic acid (HMBi) in dairy cows has been associated with improved milk production, milk protein concentrations, and nitrogen utilization (St-Pierre and Sylvester, 2005; Chen et al., 2011; Osorio et al., 2013), better immunometabolic status (Osorio et al., 2014a,b), and modified hepatic gene expression and DNA methylation pattern (Osorio et al., 2014a, 2016).

The biologically active component of $\mathrm{HMBi}$ is 2-hydroxy-4-(methylthio)butanoic acid (HMB). When supplemented in a nonesterified form, little HMB is absorbed in the rumen (St-Pierre and Sylvester, 2005; Zanton et al., 2014); however, the esterification process of HMB to various alcohols deceases ruminal degradation of the HMB molecule and results in 
postruminal HMBi bioavailability of 40 to $58 \%$ (Robert et al., 2001a,b, 2002; Schwab et al., 2001; Graulet et al., 2005; St-Pierre and Sylvester, 2005). After supplemental HMBi is absorbed across the rumen wall, it is hydrolyzed into HMB and isopropyl alcohol, and subsequently converted to Met and acetone, respectively (Graulet et al., 2005).

The liver plays a central role in Met metabolism and key hepatic genes serve as important regulatory points for controlling Met metabolism (Finkelstein, 1990; Figure 1). A previous study indicated subtle differences between DL-Met and HMB on regulating expression of key genes for Met metabolism, gluconeogenesis, and fatty acid oxidation (Zhang et al., 2016). Although it is apparent that hepatic tissue can convert D-Met to L-Met, it remains unclear if different isoforms of Met differentially affect hepatic regulation of Met pathways, and whether interactions are present between DL-Met and HMB in liver. Our objective was to examine the regulation of key genes for transmethylation (methionine adenosyltransferase 1A, MAT1A; glycine N-methyltransferase, GNMT), Met regeneration (methionine reductase, MTR; betaine-homocysteine methyltrans- ferase, $B H M T$ ), and transulfuration (cystathionine$\beta$-synthase, $C B S$; cystathionase, $C S E$ ) pathways in response to increasing concentrations of different Met sources, including D-Met, L-Met, DL-Met, HMB, and a 1:1 mixture of DL-Met and HMB in bovine hepatocytes. We hypothesized that different Met sources would be metabolized and function similarly in bovine hepatocytes and increased concentration of Met sources would decrease the expression of genes controlling methionine regeneration.

All experimental procedures involving animals were approved by the University of Wisconsin-Madison College of Agricultural and Life Sciences Animal Care and Use Committee. Four Holstein bull calves between 4 and $7 \mathrm{~d}$ old $(48 \pm 2 \mathrm{~kg}$ of BW) were used as hepatocyte donor animals. Primary hepatocytes were isolated via collagenase perfusion of the caudate process as described previously (Donkin and Armentano, 1993). Approximately $2.0 \times 10^{6}$ cells were seeded on $35-\mathrm{mm}$ Corning Primaria culture dishes (Fisher Scientific, Pittsburgh, PA) at cell density of $2.0 \times 10^{5}$ cells $/ \mathrm{cm}^{2}$ (to obtain $80 \%$ confluence) with Dulbecco's modified Eagle medium (DMEM 2902, Sigma, St. Louis, MO)

\section{Transmethylation}

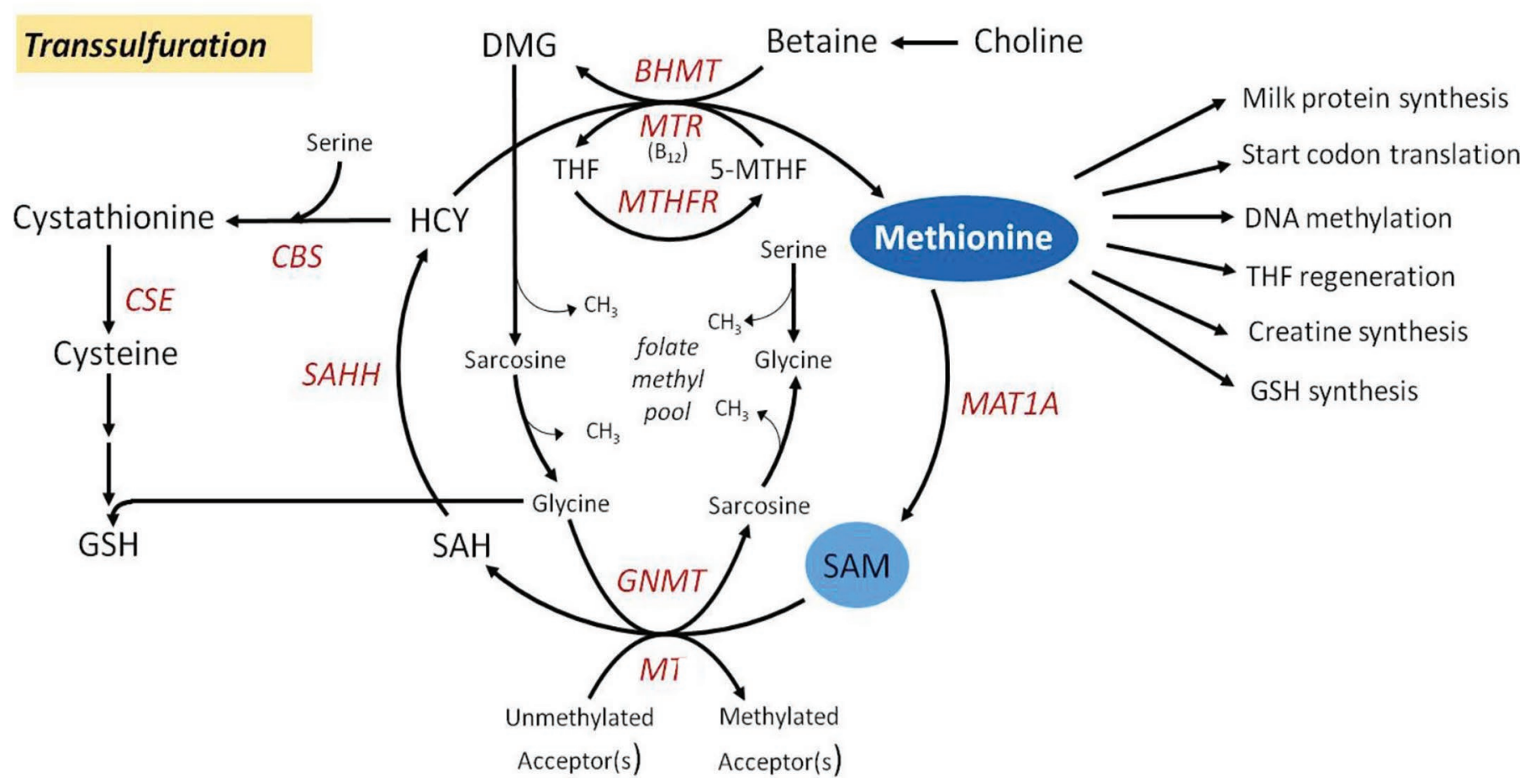

Figure 1. Hepatic Met metabolism and the biological roles of Met. Betaine-homocysteine methyltransferase $(B H M T)$, cystathionine- $\beta$ synthase $(C B S)$, cystathionase (CSE), dimethylglycine (DMG), glutathione (GSH), glycine N-methyltransferase $(G N M T)$, homocysteine (HCY), methionine adenosyltransferase 1A (MAT1A), methionine reductase (MTR), methyltransferases $(M T)$, 5-methyltetrahydrofolate (5-MTHF), S-adenosylhomocysteine (SAH), SAH hydrolase $(S A H H)$, S-adenosylmethionine (SAM), and tetrahydrofolate (THF). Adapted from Chandler and White, 2017. 
containing $20 \%$ fetal bovine serum (Sigma) and $1 \%$ antibiotic, antimycotic solution (Sigma). Four hours after seeding, the medium was aspirated and replaced with DMEM containing 10\% fetal bovine serum and $1 \%$ antibiotic, antimycotic solution.

Twenty-four hours after seeding, the medium was aspirated and replaced with Met-free DMEM containing 1\% BSA (Merck Millipore, Billerica, MA) and 1\% antibiotic, antimycotic solution. Plates were randomly assigned to treatments of $0,10,20,40 \mu M$ of D-Met, L-Met, DL-Met, HMB, or a 1:1 mixture of DL-Met and HMB, which were applied in triplicate. After $24 \mathrm{~h}$ of treatment exposure, cell lysates were collected in 0.5 $\mathrm{mL}$ of Trizol reagent (Life Technologies, Carlsbad, CA) and stored at $-80^{\circ} \mathrm{C}$ until subsequent RNA analysis.

Total RNA was isolated using Trizol reagent. Samples were quantified and quality interrogated by absorbance using a Synergy Hybrid Spectrophotometer (BioTek, Winooski, VT). Each triplicate was pooled by equal quantity and $100 \mu \mathrm{L}$ of the pooled RNA was further purified using the RNeasy Mini Kit (Qiagen Inc., Thousand Oaks, CA). A total of $0.5 \mu \mathrm{g}$ of purified RNA sample were reverse transcribed to cDNA using iScript reverse transcriptase (Bio-Rad Laboratories Inc., Hercules, CA). Gene expression was quantified with real-time PCR using SsoFast EvaGreen Supermix (Bio-Rad Laboratories Inc.) and primers used previously (Zhang and White, 2017; Supplemental Table S1; https://doi.org/10.3168/jds.2018-15098). Primers were evaluated and a single PCR product was verified using the following protocol: 1 cycle at $95^{\circ} \mathrm{C}$ for $3 \mathrm{~min} ; 45 \mathrm{cy}$ cles at $95^{\circ} \mathrm{C}$ for $5 \mathrm{~s}, 55^{\circ} \mathrm{C}$ for $5 \mathrm{~s}$; and a melt curve from $65^{\circ} \mathrm{C}$ to $95^{\circ} \mathrm{C}$ by $0.5^{\circ} \mathrm{C}$ increments for $3 \mathrm{~s}$. A cDNA pool was generated from an equivalent quantity of cDNA from each sample. A 1:4 dilution series of the cDNA pool was used to generate the standard curve. A no template control (water as a template) and no reverse transcription control (RNA pool as a template) were included in the real-time PCR analysis. All standards, controls, and samples were amplified in triplicates using the following reaction: 1 cycle at $95^{\circ} \mathrm{C}$ for $3 \mathrm{~min}$; 45 cycles at $95^{\circ} \mathrm{C}$ for $5 \mathrm{~s}, 55^{\circ} \mathrm{C}$ for $5 \mathrm{~s}$. Efficiencies of all PCR reactions were between 90 and $110 \%$ based on standard curve analysis. The quantification cycle data were transformed to starting quantity (SQ) data with Bio-Rad CFX Manager Software (version 3.1, Bio-Rad Laboratories Inc.) based on standard curves. The SQ for the 5 standards (1:4 dilutions of the cDNA pool) was defined as $0.25,0.0625,0.0156,0.0039$, and 0.00098 , respectively. The mRNA abundance of each target gene was calculated as the SQ of the target gene normalized to the arithmetic mean SQ of 3 reference genes: $18 S$, ribosomal protein S9 (RPS9), and $\alpha$-1-microglobulin/ bikunin precursor $(A M B P)$ within each sample, after interrogation to ensure the absence of a treatment effect.

Data were analyzed using PROC MIXED of SAS 9.3 (SAS Institute Inc., Cary, NC). Analysis of covariance confirmed equivalent slopes of Met source; therefore, final models contained fixed effect of source and concentration, and random effect of calf. Data are reported as least squares means and standard errors. Statistical significance was declared at $P<0.05$ and tendencies at $0.05 \leq P \leq 0.10$.

Increasing concentrations of Met tended to decrease $(P=0.08)$ expression of MAT1A, which converts Met to S-adenosyl methionine (SAM), the primary methyl donor (Figure 2). Increasing concentrations of Met did not alter $(P>0.10)$ expression of $M T R$, but decreased $(P<0.05)$ BHMT, which uses 5-methyltetrahydrofolate and betaine, respectively, to regenerate Met. Decreases in MAT1A and BHMT in the current study are consistent with a previous, similar experiment that examined the effect of DL-Met and HMB in primary bovine neonatal hepatocytes (Zhang et al., 2016). In the prior experiment, a decrease in $M T R$ expression was also observed, although the difference could have been due to the broader range of concentrations examined with a maximal dose of $60 \mu \mathrm{M}$. Decreased expression of genes associated with Met regeneration supports a reduced need for Met regeneration with increasing Met supplementation. The decreased MAT1A expression may be a regulatory mechanism to maintain constant intracellular SAM concentration when Met concentration was increased.

Increasing concentrations of Met did not alter $(P>$ 0.10) expression of GNMT, the major SAM-dependent transmethylase, or $C B S$ and $C S E$, the 2 key enzymes for cysteine generation through the transsulfuration pathway (Figure 2). Although decreased expression of $G N M T$ was observed previously during a LPS challenge in cell culture, $C B S$ and $C S E$ were not altered by the challenge (Zhang and White, 2017). Given that the current experiment did not involve an inflammatory challenge, it is not surprising that no changes were observed in expression of these genes.

The previous findings indicated that primary bovine neonatal hepatocytes only demonstrated subtle differences in response to increasing supplementation with DL-Met or DL-HMB over a broad range of concentrations (Zhang et al., 2016); however, the question of hepatocyte response to D-Met and L-Met isomers remained, especially considering the need for conversion of D-Met to L-Met by hepatic or extramammary tissues (Lapierre et al., 2012). Additionally, it is not uncommon to supplement both DL-Met and HMBi in dairy cattle rations; therefore, we were also interested in examining hepatocyte response to a mixture of DL-Met 


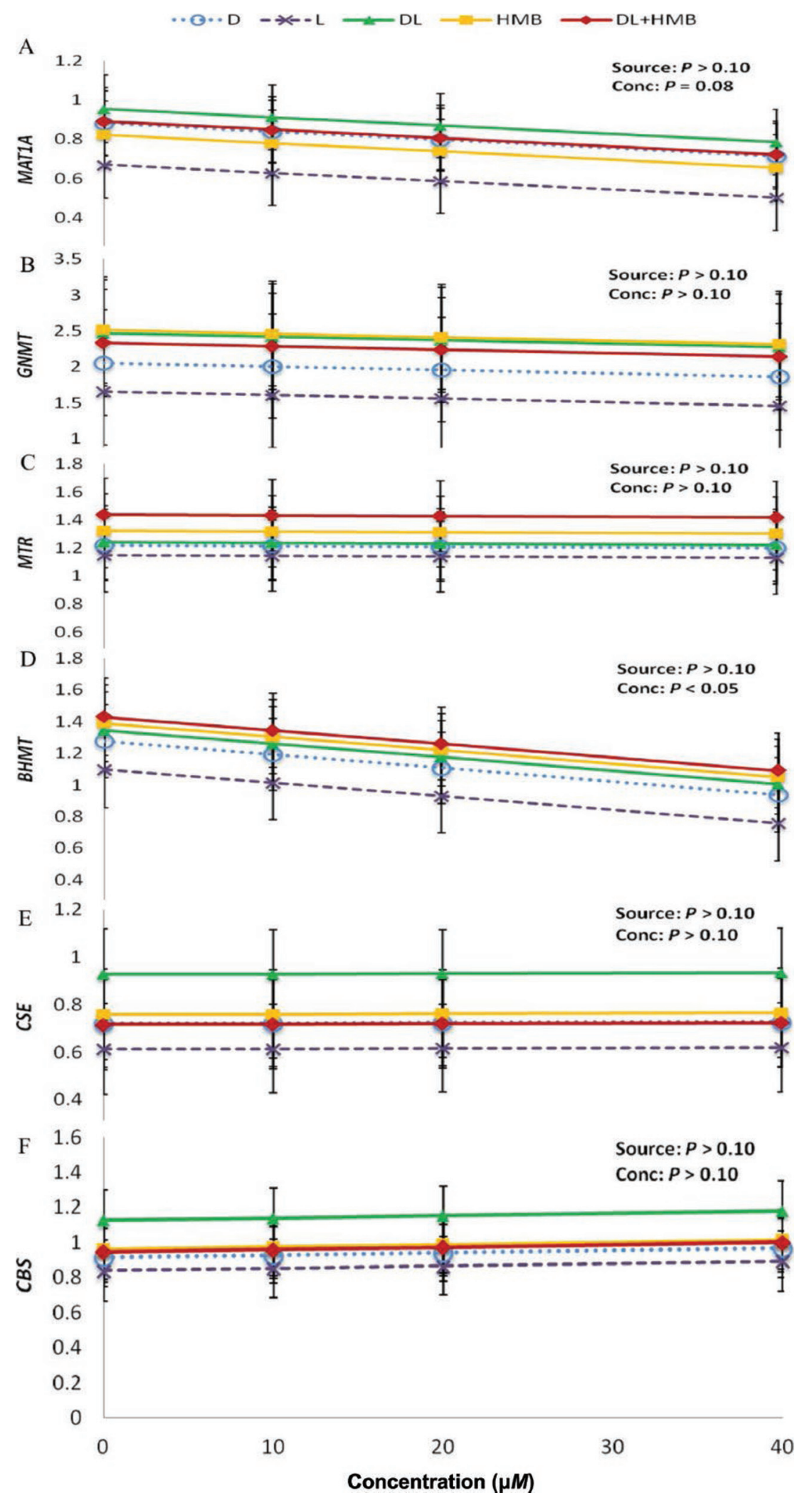

Figure 2. Effect of increasing concentrations of D-methionine (D), L-methionine (L), DL-methionine (DL), 2-hydroxy-4-(methylthio)butanoic acid (HMB), and a 1:1 mixture of DL and HMB (DL+HMB) on mRNA expression of the key enzymes including methionine adenosyltransferase 1A (A; MAT1A), glycine N-methyltransferase (B; GNMT), methionine reductase (C; MTR), betaine-homocysteine methyltransferase (D; $B H M T)$, cystathionase $(\mathrm{E} ; C S E)$, and cystathionine- $\beta$-synthase $(\mathrm{F} ; C B S)$ relative to reference genes in bovine hepatocytes. 
and DL-HMB. In the current experiment, Met source had no effect $(P>0.10)$ on mRNA expression of any genes examined. This lack of differential response of primary bovine neonatal hepatocytes to different forms of Met, HMB, or a mixture supports that expression of key hepatic genes is similarly responsive to different Met forms.

The current work did not examine the rate of conversion of D-Met or HMB to L-Met, which has previously been suggested to be a slow process (Lapierre et al., 2012). A slow conversion of D-Met to L-Met could result in delayed availability to tissues or artificially increased extracellular concentrations; however, continual dietary supply in vivo should not present a confounder. Within the current experiment, all supplemental Met was provided at the beginning of the 24-h treatment period, which was apparently sufficient time for conversion of Met forms and alterations in gene expression within the cell culture system. Further elucidation of the conversion rate by hepatocytes in vitro would require time lapse treatment and sample collection.

In conclusion, Met supplementation reduces the necessity for Met regeneration and decreased MAT1A expression may be a means to maintain constant intracellular SAM concentration despite increased Met concentration. The lack of differences among Met sources on gene expression indicates that Met sources did not differentially regulate key genes involved in Met regeneration or metabolism pathways.

\section{ACKNOWLEDGMENTS}

This research was partially funded by gifts from the Wisconsin Alumni Research Foundation (Madison). The authors thank Peter Crump (University of Wisconsin-Madison) for his assistance with the statistical analysis.

\section{REFERENCES}

Chandler, T. L., and H. M. White. 2017. Choline and methionine differentially alter methyl-carbon metabolism in bovine neonatal hepatocytes. PLoS One 12:e0171080. https://doi.org/10.1371/ journal.ponse.0171080.

Chen, Z. H., G. A. Broderick, N. D. Luchini, B. K. Sloan, and E. Devillard. 2011. Effect of feeding different sources of rumen-protected methionine on milk production and N-utilization in lactating dairy cows. J. Dairy Sci. 94:1978-1988.

Donahue, P. B., C. G. Schwab, J. D. Quigley III, and W. E. Hylton. 1985. Methionine deficiency in early-weaned dairy calves fed pelleted rations based on corn and alfalfa or corn and soybean proteins. J. Dairy Sci. 68:681-693.

Donkin, S. S., and L. E. Armentano. 1993. Preparation of extended in vitro cultures of bovine hepatocytes that are hormonally responsive. J. Anim. Sci. 71:2218-2227.

Finkelstein, J. D. 1990. Methionine metabolism in mammals. J. Nutr. Biochem. 1:228-237.
Graulet, B., C. Richard, and J. C. Robert. 2005. Methionine availability in plasma of dairy cows supplemented with methionine hydroxy analog isopropyl ester. J. Dairy Sci. 88:3640-3649.

Lapierre, H., G. Holtrop, A. G. Calder, J. Renaud, and G. E. Lobley. 2012. Is D-methionine bioavailable to the dairy cow? J. Dairy Sci. 95:353-362.

NRC. 2001. Nutrient Requirements of Dairy Cattle. 7th rev. ed. Natl. Acad. Press, Washington, DC.

Osorio, J. S., C. B. Jacometo, Z. Zhou, D. Luchini, F. C. Cardoso, and J. J. Loor. 2016. Hepatic global DNA and peroxisome proliferatoractivated receptor alpha promoter methylation are altered in peripartal dairy cows fed rumen-protected methionine. J. Dairy Sci. 99:234-244.

Osorio, J. S., P. Ji, J. K. Drackley, D. Luchini, and J. J. Loor. 2013. Supplemental Smartamine M or MetaSmart during the transition period benefits postpartal cow performance and blood neutrophil function. J. Dairy Sci. 96:6248-6263.

Osorio, J. S., P. Ji, J. K. Drackley, D. Luchini, and J. J. Loor. 2014a. Smartamine $\mathrm{M}$ and MetaSmart supplementation during the peripartal period alter hepatic expression of gene networks in 1-carbon metabolism, inflammation, oxidative stress, and the growth hormone-insulin-like growth factor 1 axis pathways. J. Dairy Sci. 97:7451-7464.

Osorio, J. S., E. Trevisi, P. Ji, J. K. Drackley, D. Luchini, G. Bertoni, and J. J. Loor. 2014b. Biomarkers of inflammation, metabolism, and oxidative stress in blood, liver, and milk reveal a better immunometabolic status in peripartal cows supplemented with Smartamine M or MetaSmart. J. Dairy Sci. 97:7437-7450.

Robert, J.-C., T. d'Alfonso, G. Etave, E. Depres, and B. Bouza. 2002. Quantifying the metabolizable methionine contribution of a liquid or powder presentation of 2-hydroxy-4(methylthio) butanoic acid isopropyl ester (HMBi). J. Dairy Sci. 85(Suppl. 1):71.

Robert, J.-C., C. Richard, and B. Bouza. 2001a. Influence of monomer and dimer forms of isopropyl ester of HMB on the supply of metabolizable methionine to the blood of ruminants. J. Dairy Sci. 84(Suppl. 1):281.

Robert, J.-C., B. K. Sloan, G. Etave, and B. Bouza. 2001b. Influence of length and ramification of the alcohol radical of esters of methionine and of 2-hydroxy-4(methylthio) butanoic acid on methionine bioavailability. J. Dairy Sci. 84(Suppl. 1):34.

Schwab, C. G., C. K. Bozak, N. L. Whitehouse, and M. M. A. Mesbah. 1992. Amino acid limitation and flow to the duodenum at four stages of lactation. 1. Sequence of lysine and methionine limitation. J. Dairy Sci. 75:3486-3502.

Schwab, C. G., L. D. Satter, and A. B. Clay. 1976. Responses of lactating dairy cows to abomasal infusions of amino acids. J. Dairy Sci. 59:1254-1270

Schwab, C. G., N. L. Whitehouse, A. M. McLaughlin, R. K. Kadariya, N. R. St-Pierre, B. K. Sloan, R. M. Gill, and J.-C. Robert. 2001 Use of milk protein concentration to estimate the methionine bioavailability of two forms of 2-hydroxy-4-methylthio butanoicacid (HMB) for lactating cows. J. Dairy Sci. 84(Suppl. 1):35.

St-Pierre, N. R., and J. T. Sylvester. 2005. Effects of 2-hydroxy4-(methylthio) butanoic acid (HMB) and its isopropyl ester on milk production and composition by Holstein cows. J. Dairy Sci. 88:2487-2497.

Zanton, G. I., G. R. Bowman, M. Vázquez-Añón, and L. M. Rode. 2014. Meta-analysis of lactation performance in dairy cows receiving supplemental dietary methionine sources or postruminal infusion of methionine. J. Dairy Sci. 97:7085-7101.

Zhang, Q., S. J. Bertics, N. D. Luchini, and H. M. White. 2016. The effect of increasing concentrations of DL-methionine and 2-hydroxy4-(methylthio)butanoic acid on hepatic genes controlling methionine regeneration and gluconeogenesis. J. Dairy Sci. 99:8451-8460.

Zhang, Q., and H. M. White. 2017. Regulation of inflammation, antioxidant production, and methyl-carbon metabolism during methionine supplementation in lipopolysaccharide challenged neonatal bovine hepatocytes. J. Dairy Sci. 100:8565-8577. 